\title{
Set Covering Model Using Greedy Heuristic Algorithm to Determine The Temporary Waste Disposal Sites in Palembang
}

\author{
Putra Bahtera Jaya Bangun', Sisca Octarina ${ }^{1,2 *}$, Rizka Aniza', Laila Hanum³ ${ }^{3}$, Fitri Maya Puspita', Siti Suzlin Supadi ${ }^{4}$ \\ ${ }^{1}$ Mathematics Department, Faculty of Mathematics and Natural Sciences, Sriwijaya University, Palembang, 30662, Indonesia \\ ${ }^{2}$ Graduate School of Science, Faculty of Mathematics and Natural Sciences, Sriwijaya University, Palembang, 30662, Indonesia \\ ${ }^{3}$ Biology Department, Faculty of Mathematics and Natural Sciences, Sriwijaya University, Palembang, 30662, Indonesia \\ ${ }^{4}$ Institute of Mathematical Sciences, University of Malaya, Kuala Lumpur, 50603, Malaysia \\ *Corresponding Author e-mail: sisca_octarina@unsri.ac.id
}

\begin{abstract}
Optimizing the facility location has a vital role in providing services to the community. This study aims to determine the Temporary Waste Disposal Site (TWDS) in Sako District, Palembang City. The distance data between each TWDS in Sako District is used to formulate the Set Covering model, consisting of the Set Covering Location Problem (SCLP) model and the p-Median Problem model. The classical approach is made by solving both models using Lingo 18.0 software. The Greedy Heuristic algorithm is used as the heuristic approach. Based on the results and discussion, Sako District consists of 4 Villages and 9 TWDS. The SCLP and pMedian Problem models with LINGO 18.0 software and the Greedy Heuristic algorithm show a difference. The study results suggest using the optimal solution resulting from the Greedy Heuristic algorithm because it can meet all requests in Sako District. Research shows that there are six optimal TWDS in Sako District. We recommend adding 14 additional TWDS facilities in Sako District to serve all requests.
\end{abstract}

Keywords

Facility Location, Temporary Waste Disposal Site, Set Covering Model, Greedy Heuristic Algorithm

Received: 28 October 2021, Accepted: 17 January 2022

https://doi.org/10.26554/sti.2022.7.1.98-105

\section{INTRODUGTION}

Rapid population growth makes Indonesia ranks $4^{\text {th }}$ in population density (Devi et al., 2016). One of the impacts of population density is the waste problem. Waste is no longer used or leftover materials and objects that are not useful and thrown away by people everywhere. To overcome indiscriminate waste disposal, the government provides Temporary Waste Disposal Sites (TWDS) facilities. TWDS is a facility that every region must own in Indonesia to maintain environmental cleanliness.

This study discusses the TWDS placement in the Sako District. According to the Sako District Strategic Plan (2019), Sako District consists of many housing complexes and has inadequate TWDS for the community. It is necessary to optimize the location of TWDS so that people can dispose of their waste in its place. The problem of processing and transporting waste in Palembang City is regulated by the Palembang City Environment and Hygiene Service (DLHK). DLHK is in charge of managing hygiene issues. According to DLHK, there are nine official TWDS in Sako District. The government has obstacles in placing the location of TWDS. This study attempts to as- sist and facilitate the selection of TWDS. Optimizing location placement is part of the Optimization problem, especially the Set Covering Problem (SCP) (Puspita et al., 2019).

SCP is a problem of integer programming to optimize the number and allocation of facility location points (Kwon et al., 2020). SCP in daily life includes allocating machines to the given task, assigning jobs to workers, optimizing the facility location to obtain optimal results, assigning garbage vehicle routes to the garbage collection site to optimize the distance and required costs, and others (Cordeau et al., 2019; Octarina et al., 2020; Sitepu et al., 2019a; Sitepu et al., 2019b; Ye and Kim, 2016). SCP has several problems, including Set Covering Location Problem (SCLP) and the $p$-Median Problem (Amarilies et al., 2020; Dzator and Dzator, 2015; Karataş et al., 2017). SCLP aims to determine the optimum number of facilities from several available facilities (Crawford et al., 2015; Puspita et al., 2019). The $p$-Median Problem minimizes the total distance or time or average travel costs to the facility so that it is possible to make an optimal choice (Tao et al., 2018).

One of the heuristic algorithms for solving SCP is the Greedy Heuristic algorithm. Greedy Heuristic Algorithm is 
an algorithm that chooses the best solution for the facilities located at each step. According to Amarilies et al. (2020), the Greedy Heuristic algorithm is the most feasible way to get a problem solution from the SCLP model and $p$-Median Problem. There are several steps to apply the Greedy Heuristic algorithm, including finding candidates that include requests, then looking for facilities to make replacements, if and only if more than one facility has been allocated. This algorithm removes every selected candidate and replaces it with every non-selected candidate location. According to Syakina and Nurdiati (2021), the Greedy Heuristic algorithm is a heuristic method that finds the optimal solution for large-scale and complicated problems. Determination of the TWDS location is completed using the exact approach and developed by the heuristic method to produce a more precise and faster solution.

Several previous studies related to SCP, especially in determining the public facility location, have been done (AhmadiJavid et al., 2017; Ardiansyah and Mardlijah, 2019; Calık and Fortz, 2019; Karatas and Yakıcı, 2018; Silva and Cunha, 2017; Sitepu et al., 2019a; Sitepu et al., 2019b). Meanwhile, research on Greedy Heuristics has been carried out by Min and $\mathrm{Xu}$ (2016) and Amarilies et al. (2020). Amarilies et al. (2020) used the Greedy Heuristic Algorithm to determine the public facility location and stated that this algorithm could provide an accurate optimal solution. So far, researches on SCP have focused solely on modeling and classical solutions (Ahmadi-Javid et al., 2017; Berman et al., 2019; Kinsht and Petrunko, 2020; Lutter et al., 2017; Wolf, 2019). A few researchers focused on heuristic solutions. Therefore, this research is aimed to complete the Set Covering model with the Greedy Heuristic algorithm to obtain the optimal TWDS location in Sako District, Palembang City.

\section{METHODS}

In this section, we discussed the method used in this research. A brief discussion of model SCLP, $p$-Median Problem, and a short description of the Greedy Heuristic algorithm can be seen in this section. The steps of this research are listed as follows:

1. Collect the names of TWDS in Sako District from DLHK Palembang City.

2. Measure the distance between each TWDS in Sako District, Palembang City using Google Maps.

3. Define variables and parameters for the SCLP model and $p$-Median Problem.

4. Formulate the SCLP and the $p$-Median Problem model.

5. Solve the SCLP and the $p$-Median Problem model using LINGO 18.0 software.

6. Implement the Greedy Heuristic Algorithm to solve the model.

7. Analyze the solution.

2.1 Set Covering Location Problem (SCLP)

SCLP is a problem in the distribution system that aims to find the optimal number of facility locations to serve all demand points (Sitepu et al., 2019b). The SCLP model can be written as follows:

Minimize

$$
Z_{S C L P}=\sum_{j \in J} a_{j}
$$

Subject to

$$
\begin{aligned}
& \sum_{j \in J} a_{j} \geq 1, \forall i \in I \\
& a_{j} \in\{0,1\}, \forall j \in J
\end{aligned}
$$

Where

$Z_{S C L P}=$ the number of facility location

$I=$ the set of demand location

$J=$ the set of facility location

$a_{j}=\left\{\begin{array}{l}1 ; \text { if a TWDS is located at } j \text {-th location } \\ 0 ; \text { otherwise }\end{array}\right.$

The objective function (1) minimizes the number of facility locations. Constraint (2) ensures that at least one facility meets each request point, and constraint (3) states that the decision variables are binary.

\section{2 p-Median Problem}

One of the fundamental problems of discrete location theory to determine point $p$ in a facility such that the sum of the distances from other points to the nearest chosen point $p$ is minimal is called the $p$-Median Problem. The $p$-Median Problem search is carried out across a finite set of points. The $p$-Median Problem aims to determine the point $p$ (center) with the sum of the distances from $n$ demand point to the nearest $p$ center (Tao et al., 2018). According to Ahmadi-Javid et al. (2017), the mathematical formulation of the $p$-Median Problem model can be written as follows: Minimize

$$
Z_{p-\text { Median }}=\sum_{i \in I} \sum_{j \in J} d_{i j} b_{i j}
$$

Subject to

$$
\begin{aligned}
& \sum_{j \in J} b_{i j}=1, \forall i \in I \\
& \sum_{j \in J} a_{j}=p \\
& b_{i j} \leq a_{j}, \forall i \in I, \forall j \in J
\end{aligned}
$$




$$
a_{j} \in\{0,1\}, b_{i j} \in\{0,1\}
$$

with

$Z_{p-\text { Median }}=$ minimum distance from demand location to facility location

$I=$ the set of demand location

$J=$ the set of facility location

$p=$ number of facility

$d_{i j}=$ distance between $i$ and $j$ location

$a_{j}=\left\{\begin{array}{l}1 ; \text { if a facility is located at } j \text {-th location } \\ 0 ; \text { otherwise }\end{array}\right.$

$b_{i j}=\left\{\begin{array}{l}1 ; \text { if a demand in i location is located at } j \text {-th location } \\ 0 ; \text { otherwise }\end{array}\right.$

\subsection{Greedy Heuristic Algorithm}

The Greedy Heuristic Algorithm is one of the algorithms used to solve optimization problems. Greedy's algorithm aims to locate facilities without capacity, known as deletion. This algorithm is executed by determining the optimal facility location point. Determining the optimal point is defined as the marginal cost of the objective function when each double route of transportation is removed from the facility location (Katayama, 2019). This algorithm is the most feasible way to generate solutions from the SCLP and $p$-Median Problem model. There are several steps in Greedy Heuristic Algorithm, including determining candidate sites that include demands, then looking for facilities to make replacements, if and only if more than one facility has been located.

The Greedy Heuristic Algorithm uses a model from SCLP. The steps in the Greedy Heuristic algorithm to get the optimal solution are

1. If $c_{i}=0, \forall i, a_{i}=1$, where $c_{i}$ is the objective function coefficient, then eliminate all constraints $a_{i}$ which has a coefficient of 1 .

2. If $c_{i}>0, \forall i$ and $a_{i}$ have no coefficient 1 in any remaining constraints, then $a_{i}=0$

3. For the remaining variables, calculate $\frac{c_{i}}{d_{1}}$ where $d_{i}$ is the number of constraints $a_{i}$, which appears with a coefficient of 1 . Choose the minimum variable $\frac{c_{i}}{d_{1}}$ and the set $a_{i}$ has a coefficient of 1 .

4. If there are no more constraints, all variable sets remaining 0 are terminated; otherwise, repeat Step (1).

\section{RESULTS AND DISCUSSION}

The list of villages names, TWDS names, and the distance between each TWDS can be seen in Tables 1 and 2 .

Table 1 describes the TWDS names in each village in Sako District. Sukamaju Village has 3 TWDS, namely TWDS Ganda Subrata in front of Yuka Housing, TWDS Pusri Sukamaju Housing, and TWDS Vila Kenten Complex. Meanwhile, Sako Village has 2 TWDS, namely TWDS BSD Complex and TWDS Griya Musi Sako Market. Sialang Village has 3
Table 1. The List of Villages and TWDS Names

\begin{tabular}{|c|c|}
\hline Villages Names & TWDS Names \\
\hline \multirow{3}{*}{ Sukamaju Village } & TWDS Ganda Subrata in front of Yuka Housing \\
\hline & TWDS Pusri Sukamaju Housing \\
\hline & TWDS Vila Kenten Complex \\
\hline \multirow{3}{*}{ Sako Village } & TWDS BSD Complex \\
\hline & TWDS Griya Musi Sako Market \\
\hline & TWDS Behind Satelit Murni Market \\
\hline \multirow[t]{2}{*}{ Sialang Village } & TWDS East Musi Raya Street \\
\hline & TWDS West Musi Raya Street \\
\hline Sako Baru Village & TWDS North Musi Raya Street \\
\hline
\end{tabular}

TWDS, namely TWDS Behind Satelit Murni Market, TWDS East Musi Raya Street, and TWDS West Musi Raya Street. Sako Baru Village has 1 TWDS, namely TWDS North Musi Raya Street.

The definition of variables and parameters for TWDS and Villages in Sako District can be seen in Table 2. Table 2 states that $a_{1}$ is TWDS Ganda Subrata in front of Yuka Housing, $a_{2}$ is TWDS Pusri Sukamaju Housing, and so on. Table 3 states the distance data between each TWDS in Sako District. According to the Regulation of the Minister of Public Works of the Republic of Indonesia Article 29 paragraph (3) regarding the Implementation of Waste Infrastructure and Facilities in the Handling of Household Waste and Types of Household Waste, the maximum distance between each TWDS is 500 meters. This distance data was obtained using Google Maps.

Table 2. Defining Variables and Parameters

\begin{tabular}{cc}
\hline Variables & Definition \\
\hline$a_{1}$ & TWDS Ganda Subrata in front of Yuka Housing \\
$a_{2}$ & TWDS Pusri Sukamaju Housing \\
$a_{3}$ & TWDS Vila Kenten Complex \\
$a_{4}$ & TWDS BSD Complex \\
$a_{5}$ & TWDS Behind Satelit Murni Market \\
$a_{6}$ & TWDS North Musi Raya Street \\
$a_{7}$ & TWDS East Musi Raya Street \\
$a_{8}$ & TWDS West Musi Raya Street \\
$a_{9}$ & TWDS Griya Musi Sako Market \\
$b_{1}$ & Sukamaju Village \\
$b_{2}$ & Sako Village \\
$b_{3}$ & Sialang Village \\
$b_{4}$ & Sako Baru Village \\
\hline
\end{tabular}

Table 3 states that $d_{12}$ is the distance from TWDS Ganda Subrata in front of Yuka Housing $\left(a_{1}\right)$ to TWDS Pusri Sukamaju Housing $\left(a_{2}\right)$ is 1,800 meters, $d_{13}$ is the distance from TWDS Ganda Subrata in front of Yuka Housing $\left(a_{1}\right)$ to TWDS Vila Kenten Complex $\left(a_{3}\right)$ is 1,700 meters and so on. 
Table 3. Distances Between Each TWDS in Sako District

\begin{tabular}{cccccccccc}
\hline$d_{i j}$ & 1 & 2 & 3 & 4 & 5 & 6 & 7 & 8 & 9 \\
\hline 1 & 0 & 1800 & 1700 & 4300 & 4900 & 3300 & 3700 & 3500 & 4200 \\
2 & 1800 & 0 & 1100 & 3500 & 4100 & 2500 & 2900 & 2700 & 3400 \\
3 & 1700 & 1100 & 0 & 3100 & 3600 & 2000 & 2400 & 2200 & 2900 \\
4 & 4300 & 3500 & 3100 & 0 & 2800 & 2500 & 2900 & 2700 & 2600 \\
5 & 4900 & 4100 & 3600 & 2800 & 0 & 1600 & 1200 & 1500 & 500 \\
6 & 3300 & 2500 & 2000 & 2500 & 1600 & 0 & 450 & 450 & 950 \\
7 & 3700 & 2900 & 2400 & 2900 & 1200 & 450 & 0 & 300 & 500 \\
8 & 3500 & 2700 & 2200 & 2700 & 1500 & 450 & 300 & 0 & 800 \\
9 & 4200 & 3400 & 2900 & 2600 & 500 & 950 & 500 & 800 & 0 \\
\hline
\end{tabular}

\subsection{Set Covering Location Problem (SCLP) Model of TWDS in Sako District}

Based on Model (1)-(3), the SCLP model of TWDS in Sako District can be seen in Model (9), with Constraints (11)-(18).

Minimize $\mathrm{Z}_{S C L P}=a_{1}+a_{2}+a_{3}+a_{4}+a_{5}+a_{6}+a_{7}+a_{8}+a_{9}$

Subject to

$$
\begin{aligned}
a_{1} & \geq 1 \\
a_{2} & \geq 1 \\
a_{3} & \geq 1 \\
a_{4} & \geq 1 \\
a_{5}+a_{9} & \geq 1 \\
a_{6}+a_{7}+a_{8} & \geq 1 \\
a_{6}+a_{7}+a_{8}+a_{9} & \geq 1 \\
a_{5}+a_{7}+a_{9} &
\end{aligned}
$$

$a_{1}, a_{2}, a_{3}, a_{4}, a_{5}, a_{6}, a_{7}, a_{8}, a_{9} \in\{0,1\}$ and integer

Model (9) minimizes the number of candidate locations. Constraints (11)-(17) are the constraints for each demand point that has a distance $\leq 500$ meters, and Constraint (18) states that each variable is binary. By using the LINGO 18.0 software, the optimal solution of TWDS location states that $a_{1}=a_{2}=$ $a_{3}=a_{4}=a_{8}=a_{9}=1$ which means that the candidate locations should be in 6 TWDS locations as follows:

1. TWDS Ganda Subrata in front of Yuka Housing

2. TWDS Pusri Sukamaju Housing

3. TWDS Vila Kenten Complex

4. TWDS BSD Complex

5. TWDS West Musi Raya Street

6. TWDS Griya Musi Sako Market
$3.2 p$-Median Problem Model of TWDS in Sako District The $p$-Median Problem model uses data on the location of TWDS and the demand from the Villages in Sako District. The location of TWDS is indicated by $x_{j}$, and the location of the villages is denoted by $y_{i}$. Based on the results of the SCLP model, there are six optimal TWDS located in 4 Villages in Sako District. The $p$-Median Problem model is formulated according to Equation (4) and Constraints (5) to (8). The distance data from the facility point to the demand point is shown in Table 4.

Table 4. Distance Between Villages and TWDS in Sako District

\begin{tabular}{ccccccc}
\hline$d_{i j}$ & 1 & 2 & 3 & 4 & 8 & 9 \\
\hline 1 & 750 & 1100 & 1100 & 4300 & 3100 & 3600 \\
2 & 4200 & 3300 & 2800 & 2600 & 800 & 550 \\
3 & 3800 & 2800 & 2400 & 3500 & 1400 & 650 \\
4 & 4000 & 3100 & 2600 & 2500 & 950 & 800 \\
\hline
\end{tabular}

Table 4 states that $d_{11}$ is the distance from Sukamaju Village $\left(b_{1}\right)$ to TWDS Ganda Subrata in front of Yuka Housing $\left(a_{1}\right)$ is 750 meters, $d_{12}$ is the distance from Sukamaju Village $\left(b_{1}\right)$ to TWDS Pusri Sukamaju Housing $\left(a_{2}\right)$ is 1,100 meters, and so on. Furthermore, for the formulation of the objective function, the notation $y_{i j}$ is used, which states the request in Village $i$ is assigned to the $j-t h$ TWDS. The $p$-Median Problem model of TWDS in Sako District is stated in Model (19)-(32). Minimize

$$
\begin{aligned}
Z_{p-\text { Median }}= & 750 b_{11}+1100 b_{12}+1100 b_{13}+4300 b_{14}+ \\
& 3100 b_{18}+3600 b_{19}+4200 b_{21}+3300 b_{22}+ \\
& 2800 b_{23}+2600 b_{24}+800 b_{28}+550 b_{29}+ \\
& 3800 b_{31}+2800 b_{32}+2400 b_{33}+3500 b_{34}+ \\
& 1400 b_{38}+650 b_{39}+4000 b 41+3100 b_{42}+ \\
& 2600 b_{43}+2500 b_{44}+950 b_{48}+800 b_{49}
\end{aligned}
$$




$$
\begin{aligned}
b_{11}+b_{12}+b_{13}+b_{14}+b_{18}+b_{19} & =1 \\
b_{21}+b_{22}+b_{23}+b_{24}+b_{28}+b_{29} & =1 \\
b_{31}+b_{32}+b_{33}+b_{34}+b_{38}+b_{39} & =1 \\
b_{41}+b_{42}+b_{43}+b_{44}+b_{48}+b_{49} & =1 \\
a_{1}+a_{2}+a_{3}+a_{4}+a_{8}+a_{9} & =6 \\
b_{11}, b_{21}, b_{31}, b_{41} & \leq a_{1} \\
b_{12}, b_{22}, b_{32}, b_{42} & \leq a_{2} \\
b_{13}, b_{23}, b_{33}, b_{43} & \leq a_{3} \\
b_{14}, b_{24}, b_{34}, b_{44} & \leq a_{4} \\
b_{18}, b_{28}, b_{38}, b_{48} & \leq a_{8}
\end{aligned}
$$

$$
b_{19}, b_{29}, b_{39}, b_{49} \leq a_{9}
$$

$b_{11}, b_{12}, b_{13}, b_{14}, b_{18}, b_{19}, b_{21}, b_{22}, b_{23}, b_{24}, b_{28}, b_{29}, b_{31}, b_{32}$, $b_{33}, b_{34}, b_{38}, b_{39}, b_{41}, b_{42}, b_{43}, b_{44}, b_{48}, b_{49} \geq 0$ and integer

$$
a_{1}, a_{2}, a_{3}, a_{4}, a_{8}, a_{9} \geq 0 \text { and integer }
$$

The objective function (19) minimizes the total distance between Villages and TWDS. Constraints (21)-(24) are the constraints for demand location. Constraint (25) shows the number of facility locations. Meanwhile, Constraints (26)-(30) ensure that the demand locations correspond to the optimal TWDS from the SCLP solutions. Each variable is binary and shown in Constraints (31)-(32). The optimal distance based on the solution of $p$-Median Problem model is 2,750 meters with $b_{11}=$ $b_{29}=b_{39}=b_{49}=1$ which mean:

1. The demand in Sukamaju Village $\left(b_{1}\right)$ is allocated at TWDS Ganda Subrata in front of Yuka Housing $\left(a_{1}\right)$.

2. The demand in Sako Village $\left(b_{2}\right)$ is allocated at TWDS Griya Musi Sako Market $\left(a_{9}\right)$.

3. The demand in Sialang Village $\left(b_{3}\right)$ is allocated at TWDS Griya Musi Sako Market $\left(a_{9}\right)$.

4. The demand in Sako Baru Village $\left(b_{4}\right)$ is allocated at TWDS Griya Musi Sako Market $\left(a_{9}\right)$.

\subsection{Implementation of The Greedy Heuristic Algorithm in Solving The SCP Model}

Completing the SCP model used the distance data in Table 3 to obtain Tables 5 and 6 . The process of implementing the Greedy Heuristic Algorithm to the model is stated as follows.

Table 5. Objective Function of SCLP Model

$\begin{array}{cccccccccc}\text { TWDS } & 1 & 2 & 3 & 4 & 5 & 6 & 7 & 8 & 9 \\ \text { Parameter } c_{i} & 1 & 1 & 1 & 1 & 1 & 1 & 1 & 1 & 1\end{array}$

The yellow line shows the TWDS in Sako District. The green line shows the parameter $c_{i}$, where $c_{i}$ is the objective function coefficient of each, $i=1,2,3,4,5,6,7,8$, 9, all of which are 1.

Table 6. Constraints of SCLP Model

\begin{tabular}{cccccccccc}
\hline Constraint & $a_{1}$ & $a_{2}$ & $a_{3}$ & $a_{4}$ & $a_{5}$ & $a_{6}$ & $a_{7}$ & $a_{8}$ & $a_{9}$ \\
\hline First & 1 & 0 & 0 & 0 & 0 & 0 & 0 & 0 & 0 \\
Second & 0 & 1 & 0 & 0 & 0 & 0 & 0 & 0 & 0 \\
Third & 0 & 0 & 1 & 0 & 0 & 0 & 0 & 0 & 0 \\
Fourth & 0 & 0 & 0 & 1 & 0 & 0 & 0 & 0 & 0 \\
Fifth & 0 & 0 & 0 & 0 & 1 & 0 & 0 & 0 & 1 \\
Sixth & 0 & 0 & 0 & 0 & 0 & 1 & 1 & 1 & 0 \\
Seventh & 0 & 0 & 0 & 0 & 0 & 1 & 1 & 1 & 1 \\
Eighth & 0 & 0 & 0 & 0 & 0 & 1 & 1 & 1 & 0 \\
Ninth & 0 & 0 & 0 & 0 & 0 & 0 & 1 & 0 & 1 \\
\hline
\end{tabular}

Table 6 explains that the coefficient constraint with a value of 1 indicates the distance between TWDS is less than 500 meters. In comparison, the coefficient constraint with a value of 0 means the distance between TWDS is more than 500 meters.

\section{First Iteration}

Step 1

If $c_{i}=0, \forall i, a_{i}=1$, where $c_{i}$ is objective function coefficient, $i=1,2,3,4,5,6,7,8,9$. Eliminate all constraints where $a_{i}$ has a coefficient of 1 . We go to Step 2 because all values of $c_{i}$ in the objective function are greater than 0 .

Step 2

If $c_{i}>0, \forall i$ and $a_{i}$ does not have a coefficient of 1 in any of the remaining constraints then $a_{i}=0$. In this step, first calculate $d_{i}$, where $d_{i}$ is the number of constraints $x_{i}$ with a coefficient of 1 to obtain Table 7 .

Table 7. Renewal Constraints Phase 1

\begin{tabular}{cccccccccc}
\hline Constraint & $a_{1}$ & $a_{2}$ & $a_{3}$ & $a_{4}$ & $a_{5}$ & $a_{6}$ & $a_{7}$ & $a_{8}$ & $a_{9}$ \\
\hline First & 1 & 0 & 0 & 0 & 0 & 0 & 0 & 0 & 0 \\
Second & 0 & 1 & 0 & 0 & 0 & 0 & 0 & 0 & 0 \\
Third & 0 & 0 & 1 & 0 & 0 & 0 & 0 & 0 & 0 \\
Fourth & 0 & 0 & 0 & 1 & 0 & 0 & 0 & 0 & 0 \\
Fifth & 0 & 0 & 0 & 0 & 1 & 0 & 0 & 0 & 1 \\
Sixth & 0 & 0 & 0 & 0 & 0 & 1 & 1 & 1 & 0 \\
Seventh & 0 & 0 & 0 & 0 & 0 & 1 & 1 & 1 & 1 \\
Eighth & 0 & 0 & 0 & 0 & 0 & 1 & 1 & 1 & 0 \\
Ninth & 0 & 0 & 0 & 0 & 0 & 0 & 1 & 0 & 1 \\
$d_{i}$ & 1 & 1 & 1 & 1 & 2 & 3 & 4 & 3 & 3 \\
\hline
\end{tabular}

It can be seen in Table 7, there is no constraint $a_{i}=0$, so go to Step 3.

Step 3

For the remaining variables, calculate $\frac{c_{i}}{d_{i}}$ where $d_{i}$ is the number of constraints $a_{i}$ with a coefficient of 1 . Choose the 
minimum variable $\frac{c_{i}}{d_{i}}$ and the set $a_{i}$ has a coefficient of 1 . The calculation results can be seen in Table 8 .

Table 8. Renewal Constraints Phase 2

\begin{tabular}{cccccccccc}
\hline Constraint & $a_{1}$ & $a_{2}$ & $a_{3}$ & $a_{4}$ & $a_{5}$ & $a_{6}$ & $a_{7}$ & $a_{8}$ & $a_{9}$ \\
\hline First & 1 & 0 & 0 & 0 & 0 & 0 & 0 & 0 & 0 \\
Second & 0 & 1 & 0 & 0 & 0 & 0 & 0 & 0 & 0 \\
Third & 0 & 0 & 1 & 0 & 0 & 0 & 0 & 0 & 0 \\
Fourth & 0 & 0 & 0 & 1 & 0 & 0 & 0 & 0 & 0 \\
Fifth & 0 & 0 & 0 & 0 & 1 & 0 & 0 & 0 & 1 \\
Sixth & 0 & 0 & 0 & 0 & 0 & 1 & 1 & 1 & 0 \\
Seventh & 0 & 0 & 0 & 0 & 0 & 1 & 1 & 1 & 1 \\
Eighth & 0 & 0 & 0 & 0 & 0 & 1 & 1 & 1 & 0 \\
Ninth & 0 & 0 & 0 & 0 & 0 & 0 & 1 & 0 & 1 \\
$d_{i}$ & 1 & 1 & 1 & 1 & 2 & 3 & 4 & 3 & 3 \\
$c_{i}$ & 1 & 1 & 1 & 1 & 1 & 1 & 1 & 1 & 1 \\
$\frac{c}{d_{i}}$ & 1 & 1 & 1 & 1 & 0.5 & 0.333 & 0.25 & 0.333 & 0.333 \\
\hline
\end{tabular}

Columns and rows in blue show the removal of coefficient 1 and the updating of the values of $d_{i}$ and $\frac{c_{i}}{d_{i}}$. As shown in Table 9, the minimum $\frac{c_{i}}{d_{i}}$ is found at $a_{7}$, so $a_{7}=1$. Remove all constraints on $a_{7}$ which has a coefficient of 1 i.e. $6,7,8$, dan 9 . Because some constraints are removed, the values of $d_{i}$ and $\frac{c_{i}}{d_{i}}$ are also updated, we got Tables 9 and 10.

Table 9. Renewal Objective Function Phase 1

\begin{tabular}{cccccccccc}
\hline TWDS & 1 & 2 & 3 & 4 & 5 & 6 & 7 & 8 & 9 \\
Parameter $c_{i}$ & 1 & 1 & 1 & 1 & 1 & 1 & 1 & 1 & 1 \\
\hline First Solution & \multicolumn{1}{c}{} \\
\hline
\end{tabular}

Table 10. Elimination of Constraints Phase 3

\begin{tabular}{cccccccccc}
\hline Constraint & $a_{1}$ & $a_{2}$ & $a_{3}$ & $a_{4}$ & $a_{5}$ & $a_{6}$ & $a_{7}$ & $a_{8}$ & $a_{9}$ \\
\hline First & 1 & 0 & 0 & 0 & 0 & 0 & 0 & 0 & 0 \\
Second & 0 & 1 & 0 & 0 & 0 & 0 & 0 & 0 & 0 \\
Third & 0 & 0 & 1 & 0 & 0 & 0 & 0 & 0 & 0 \\
Fourth & 0 & 0 & 0 & 1 & 0 & 0 & 0 & 0 & 0 \\
Fifth & 0 & 0 & 0 & 0 & 1 & 0 & 0 & 0 & 1 \\
$d_{i}$ & 1 & 1 & 1 & 1 & 1 & 0 & & 0 & 1 \\
$c_{i}$ & 1 & 1 & 1 & 1 & 1 & 1 & & 1 & 1 \\
$\frac{c_{i}}{d_{i}}$ & 1 & 1 & 1 & 1 & 1 & 0 & & 0 & 1 \\
\hline
\end{tabular}

In Table 10, it can be seen in the blue column showing that the deletion of $a_{7}$ resulted in the value of constraint $a_{6}$ and $a_{8}$ being 0 .

Step 4

If there are no more constraints, all variable sets remaining 0 are terminated, otherwise repeat Step 1. Step 4 is not yet applicable because in the first iteration there are still many obstacles, so it is repeated to Step 1 . The process continues until iteration 6 and is obtained in Table 11. Table 11 shows that there are no remaining constraints, so the iteration stops.

In this sixth iteration, there are no remaining constraints, so the iteration is complete. The optimal solutions obtained
Table 11. Renewal Objective Function Phase 1

\begin{tabular}{cccccccccc}
\hline TWDS & 1 & 2 & 3 & 4 & 5 & 6 & 7 & 8 & 9 \\
Parameter $c_{i}$ & 1 & 1 & 1 & 1 & 1 & 1 & 1 & 1 & 1 \\
\hline First Solution & & & & & & & 1 & & \\
Second Solution & & & & & & 0 & 1 & 0 & \\
Third Solution & & & & & 1 & 0 & 1 & 0 & \\
Fourth Solution & & & & & 1 & 0 & 1 & 0 & 0 \\
Fifth Solution & 1 & & & & 1 & 0 & 1 & 0 & 0 \\
Fifth Solution & 1 & & & 1 & 1 & 0 & 1 & 0 & 0 \\
Seventh Solution & 1 & 1 & & 1 & 1 & 0 & 1 & 0 & 0 \\
Eighth Solution & 1 & 1 & 1 & 1 & 1 & 0 & 1 & 0 & 0 \\
\hline
\end{tabular}

from the Greedy Heuristic Algorithm are $a_{1}=a_{2}=a_{3}=a_{4}=a_{5}=$ $a_{7}=1$ which mean the optimal TWDS are:

1. TWDS Ganda Subrata in front of Yuka Housing at Sukamaju Village.

2. TWDS Pusri Sukamaju Housing at Sukamaju Village.

3. TWDS Vila Kenten Complex at Sukamaju Village.

4. TWDS BSD Complex at Sako Village.

5. TWDS Behind Satelit Murni Market at Sialang Village.

6. TWDS East Musi Raya Street at Sialang Village.

After completing the SCP model with the Greedy Heuristic Algorithm, the optimal TWDS in Sukamaju, Sako, and Sialang villages is obtained, so it is necessary to recommend a new TWDS in Sako Baru Village in Sako District, Palembang City. Several other locations are still not optimal, so it is recommended that there are an additional 14 new TWDS facilities in Sako District to serve all demands.

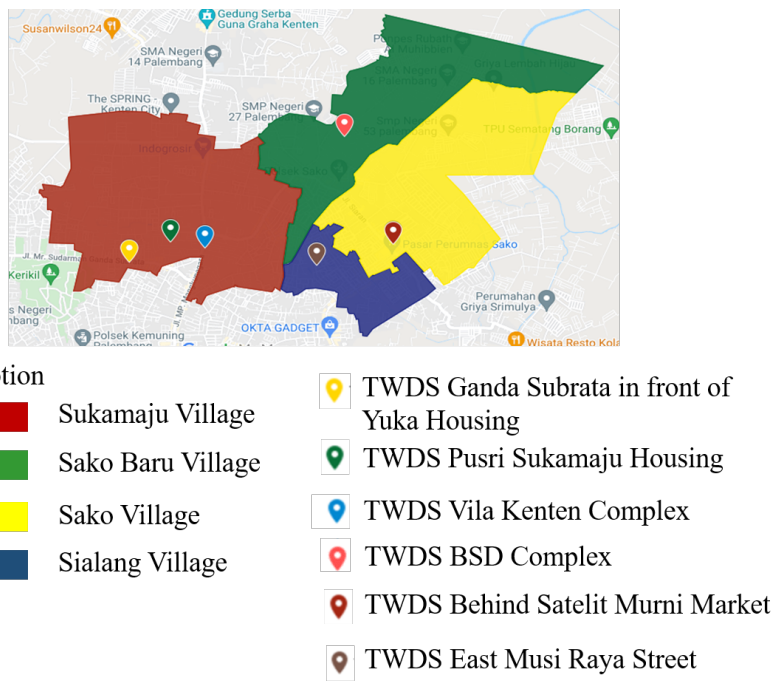

Figure 1. The Optimal TWDS in Sako District

\section{CONGLUSION}

Based on the results and discussion on determining the optimal location of TWDS in Sako District, it can be concluded that 
the SCLP model produces six optimal TWDS that can be used and utilized by the community in Sako District. While in the $p$-Median problem model, it is found that the request for 4 Villages in Sako District is placed at the closest facility locations to minimize the distance traveled. The implementation of the Greedy Heuristic Algorithm shows several differences in the optimal location obtained compared to the results of the SCP model. This study recommends the results of the Greedy Heuristic Algorithm as the optimal solution for placing TWDS in Sako District. The optimal TWDS can be seen in Figure 1. Further research can apply other heuristic methods, such as the Genetics and the Hill Climbing method. The next model can add other factors such as the capacity of TWDS and waste transportation route.

\section{ACKNOWLEDGEMENT}

The research or publication of this article was funded by DIPA of Public Service Agency of Sriwijaya University 2021. SP DIPA-023.17.2.677515/2021, on November 23, 2020. In accordance with the Rector's Decree Number: 0010/UN9/SK.LP 2M.PT/2021, on April 28, 2021.

\section{REFERENCES}

Ahmadi-Javid, A., P. Seyedi, and S. S. Syam (2017). A Survey of Healthcare Facility Location. Computers and Operations Research, 79; 223-263

Amarilies, H. S., A. P. Redi, I. Mufidah, and R. Nadlifatin (2020). Greedy Heuristics for The Maximum Covering Location Problem: A Case Study of Optimal Trashcan Location in Kampung Cipare-Tenjo-West Java. IOP Conference Series: Materials Science and Engineering, 847; 012007

Ardiansyah, A. and Mardlijah (2019). Determination of Location and Numbers of Monorail Stops in Surabaya with Max Covering Problem Model. Journal of Physics: Conference Series, 1373; 012035

Berman, O., Z. Drezner, and D. Krass (2019). The Multiple Gradual Cover Location Problem. Journal of The Operational Research Society, 70(6); 931-940

Çalık, H. and B. Fortz (2019). A Benders Decomposition Method for Locating Stations in a One-Way Electric Car Sharing System Under Demand Uncertainty. Transportation Research Part B: Methodological, 125; 121-150

Cordeau, J. F., F. Furini, and I. Ljubić (2019). Benders Decomposition for Very Large Scale Partial Set Covering and Maximal Covering Location Problems. European Journal of Operational Research, 275(3); 882-896

Crawford, B., R. Soto, N. Berríos, F. Johnson, and F. Paredes (2015). Solving The Set Covering Problem with Binary Cat Swarm Optimization. International Conference in Swarm Intelligence, $\mathbf{5} ; 41-48$

Devi, S., A. Fatchiya, and D. Susanto (2016). Kapasitas Kader Dalam Penyuluhan Keluarga Berencana di Kota Palembang, Provinsi Sumatera Selatan. Jurnal Penyuluhan, 12(2); 144156. (in Indonesia)
Dzator, M. and J. Dzator (2015). An Efficient Modified Greedy Algorithm for The $p$-Median Problem. CQUniversity; $1855-$ 1861

Karataş, M., N. Razi, and H. Tozan (2017). A Multi-Criteria Assessment of The $p$-Median, Maximal Coverage and $p$ Center Location Models. Strojarski Facultet, 24; 399-407

Karatas, M. and E. Yakıcı (2018). An Iterative Solution Approach to a Multi-Objective Facility Location Problem. Applied Soft Computing, 62; 272-287

Katayama, N. (2019). A Combined Fast Greedy Heuristic for The Capacitated Multicommodity Network Design Problem. Journal of The Operational Research Society, 70(11); 19831996

Kinsht, N. and N. Petrunko (2020). Multiple Partial Discharge Diagnostics as a Set Covering Problem. 2020 International Russian Automation Conference (RusAutoCon). ; 777-781

Kwon, Y. S., B. K. Lee, and S. Y. Sohn (2020). Optimal Location-Allocation Model for The Installation of Rooftop Sports Facilities in Metropolitan Areas. European Sport Management Quarterly, 20(2); 189-204

Lutter, P., D. Degel, C. Büsing, A. M. Koster, and B. Werners (2017). Improved Handling of Uncertainty and Robustness in Set Covering Problems. European Journal of Operational Research, 263(1); 35-49

Min, F. and J. Xu (2016). Semi-Greedy Heuristics for Feature Selection with Test Cost Constraints. Granular Computing, 1(3); 199-211

Octarina, S., D. G. Juita, N. Eliyati, and P. B. J. Bangun (2020). Set Covering Model in Solving Multiple Cutting Stock Problem. Science and Technology Indonesia, 5(4); 121-130

Sako District Strategic Plan.(2019). Rencana Strategis (Renstra) Tahun 2019 - 2023 Pemerintah Kota Palembang (Issue 01) (in Indonesia)

Puspita, F. M., S. Octarina, and H. Pane (2019). Pengoptimalan Lokasi Tempat Pembuangan Sementara (TPS) Menggunakan Greedy Reduction Algorithm (GRA) di Kecamatan Kemuning. Annual Research Seminar (ARS), 4; 267-274. (in Indonesia)

Silva, M. R. and C. B. Cunha (2017). A Tabu Search Heuristic for The Uncapacitated Single Allocation $p$-Hub Maximal Covering Problem. European Journal of Operational Research, 262(3); 954-965

Sitepu, R., F. M. Puspita, and S. Romelda (2019a). Covering Based Model Dalam Pengoptimalan Lokasi IGD Rumah sakit. Annual Research Seminar (ARS), 4; 261-266 (in Indonesia)

Sitepu, R., F. M. Puspita, S. Romelda, A. Fikri, B. Susanto, and H. Kaban (2019b). Set Covering Models in Optimizing The Emergency Unit Location of Health Facility in Palembang. Journal of Physics: Conference Series, 1282; 012008

Syakina, L. and S. Nurdiati (2021). Studi Literatur Analisis Distribusi Masalah Lokasi Fasilitas untuk Logistik Bantuan Kemanusiaan. Jurnal Pijar Mipa, 16(2); 207-214 (in Indonesia)

Tao, Z., Q. Zheng, and H. Kong (2018). A Modified Gravity 
p-Median Model for Optimizing Facility Locations. Journal of Systems Science and Information, 6(5); 421-434

Wolf, G. W. (2019). Location Covering Models: History, Applications and Advancements (Advances in Spatial Science) International Journal of Geographical Information Science,
633(11); 2334-2335

Ye, H. and H. Kim (2016). Locating Healthcare Facilities Using a Network-Based Covering Location Problem. GeoJournal, 81(6); 875-890 